Original Research Paper

\title{
The Income Stabilization Tool: Assessing the Hypothesis of a National Mutual Fund in Italy
}

\author{
${ }^{1}$ Capitanio Fabian, ${ }^{2}$ Felice Adinolfi and ${ }^{2}$ Jorgelina Di Pasquale \\ ${ }^{I}$ University of Naples, "Federico II", Italy \\ ${ }^{2}$ Department of Veterinary Medical Science, University of Bologna, Italy
}

\author{
Article history \\ Received: 10-01-2015 \\ Revised: $10-03-2016$ \\ Accepted: 17-03-2016 \\ Corresponding Author: \\ Fabian Capitanio \\ University of Naples, \\ "Federico II", \\ Via Università n. 96 \\ 80055 Portici, Italy \\ E-mail: fabian.capitanio@unina.it
}

\begin{abstract}
With the gradual phasing out of guarantees provided by the CAP to European farmers in terms of the stabilization of markets, the issue of risk management tools has gradually acquired an ever-higher profile that has resulted in a series of innovations that initially enlivened the 2009 Health Check followed by the proposed Commission regulation for rural development policy 2014-2020. In particular, the latter introduces a new measure, called the Income Stabilization Tool (IST), aimed at supporting income risk management for agricultural enterprises through the use of mutual funds. The aim of this work is twofold; to emphasize the need of new regulation aimed to foster the implementation of the IST and to assess the public cost associated by estimates the farmer demand for the tool.
\end{abstract}

Keywords: Risk Management, Income Stabilization Tool, Common Agricultural Policy

\section{Introduction}

The topic of risk management in agriculture has been at the margins of the European debate since the EU policy for agriculture sector has ensured mechanisms to stabilize the markets (Enjolras et al., 2012). The Common Agriculture Policy (CAP) thanks to a wide range of measures-institutional prices, intervention storage, export refunds, direct payments-has taken away most of the risks to which farmers are exposed (Capitanio et al., 2011; Meuwissen et al., 2011). Moreover, in the last decades the absence of an EU common framework has generated the development of several national hedging instruments and programs within EU Member States (MS) that are profoundly different in terms of both financial resources allocated and operating mechanism. With the advance of the CAP reform process, launched by the MacSharry reform (1992) and continued through Agenda 2000 (1999). Fischler reform (2003), the "CAP Health Check" in 2009 the level of European protection has rapidly decreased and consequently the competitive pressure on EU farmers has increased (Majesky, 2008) and in recent years several market crisis have threatened the viability of some farming systems (De Castro et al., 2011; 2012).

This has led towards the intensification of the debate on risk management in EU agriculture policy and in particular on the field of the individual instrument for managing income risk (Cafiero et al., 2007; Garrido and Bielza, 2008; Meuwissen et al., 2011; Capitanio et al., 2011). The first step in including risk management tools in the CAP was the introduction in the "Health Check" of the opportunity for the MS to use part of the funds allocated for direct payments in order to promote farmers' access to insurance and/or mutual funds for adverse climatic events, animal and plant diseases, pest, infestation and environmental incidents. With the recent CAP reform (2013) a step forward has been made providing general common rules in subsiding farmer's access to risk management instrument (De Castro et al., 2012). In the CAP 2014-2020 a specific chapter of rural development regulation is devoted to risk management ((EC, 2013) Regulation (EU) no 1305/2013, artt.35-39) and in particular it introduces a new measure, the Income Stabilization Tool (IST) aimed at providing to EU farmers an overall coverage to all form of risk, supporting risk management focus on farmer's income. The IST aims to create a safety net for farmers, protecting them from the negative consequences that may arise from adverse trends in income.

The IST combines all farm's insurable risk into a single contract (Pigeon et al., 2012) and it has been shaped to be included in the "green box" of the World Trade Organization (WTO) since the compensation 
payments are associated with income loss exceeding the average income of the individual farmer, calculated as the average income of the last three years, or on the basis of the income of the last five years excluding the minimum and maximum years observed (Anton et al., 2011).

Article 40 Reg.1305/2013 states IST operating in the form of mutual funds, with public financial contribution to cover part of the compensation paid by the fund to farmers. In order to calculate the reference parameters for any possible compensation the Regulation provides the definition of "income", which is to be understood as the difference between total revenue from sales made by the farmers, plus all public payments and the input costs. This definition would seem to lay out the reference parameters with the added value.

In addition to the minimum requirement of loss of income $(30 \%)$ for farm access to the resources of the fund, the measure defines further thresholds. In particular, the maximum level of loss that farmers can be compensated by the fund it is set at $70 \%$, with the maximum public participation equal to $65 \%$ of compensation paid by the fund $(65 \%$ of $70 \%$ of the income loss encountered). In this regard it should be noted, that the public financial contributions can only offset a portion of the compensation paid to farmers from the fund, or, in addition, as the contribution on interest payments on commercial loans taken out by the fund to compensate farmers in the case of a crisis, all in accordance with the highest level of public participation allowed of $65 \%$.

In this study we focus on estimating both the cost of the implementation of the IST in Italy and the economic viability of the relating mutual fund, assuming for the latter the creation of a unique fund at country level.

\section{Methodology}

On the basis of the article 40 provisions, participation in the IST can mainly be attributed to the role played by the three following variables:

- The sum that the farm involving in the fund pays annually" $(p)$

- The "guaranteed income limit" (y)-assumed as the average three years value addedd

- The 'willingness to pay'-WTP$(y)$-for each company (that will depend on its risk aversion, the time distribution of its revenue and the threshold guaranteed by the contract)

Given a particular time horizon $\mathrm{T}$, the overall benefit obtained from the membership of the IST will be formally equal to:

$$
W I P_{i}^{\circ}(\Psi)=\frac{1}{T} \sum_{i=1}^{T} \max \left\{\Psi-y_{i, t}, 0\right\}
$$

The IST membership will be required by farmers willingness to pay more-or at least equal-than the cost of the participation to the mutual fund.

The overall demand will therefore be equal to the sum of individual demands of companies for whom the willingness to pay for an instrument that guarantees for losses of $>30 \%$ of historical mean income is $\geq p$ :

$$
D_{i}(\pi, \psi)=\sum_{i=1}^{N} \gamma_{i} b_{i}
$$

where, $h_{i}$ is the income of the i-th farm and $g_{i}$ represents a dichotomous index:

$$
\gamma_{i}=\left\{\begin{array}{l}
1 \text { seWTP }(\psi) \geq \pi \\
0 \text { otherwise }
\end{array}\right.
$$

For each non-degenerate distribution of income the following demand function will be have to be respected:

$$
\partial D \pi, \psi) \partial \pi<0 \text { e } \partial D \pi, \psi) \partial \pi>0
$$

Farms with low variability in income over time will, of course, exhibit a lower WTP while firms with high variance, in contrast, will be willing to pay more to join the same fund.

In terms of functioning, each contract will entail revenues (derived from fees collected) and pay-outs (for insurance claims met) for the fund on an annual basis.

Under the assumption of "stationarity" of the distribution of the beneficiary incomes deriving from coverage, the performance of the fund will:

$$
P(\pi, \psi)=\sum_{i=1}^{N}\left\{\gamma_{i} E\left(h_{i t}\left[\pi-\max \left\{\psi-y_{i t}, 0\right\}\right]\right)-\gamma_{i} h_{i} C\right\}
$$

The total administrative costs (fixed and per unit) for the management of the fund, are identified using $C$.

The total costs of $C$ are treated as a fixed sum for practical reasons of methodology.

The trend of this function will depend on the income distribution, even if, in general, it is presumed that it takes the form of an inverted "U", starting from values that are certainly negative at a level of adhesions equal to zero (when all the farms enter the fund, without, however, any income for the fund itself).

By increasing the level of the premium, the total value of the sum of the premiums collected will rise and, simultaneously, the amount of compensation paid will be reduced as some companies (those with low levels of risk and/or risk aversion) will no longer participate in the fund. The size of its profit, will therefore reach a maximum and thereafter decrease. The fact that, at a certain point, the level of assets begins to decrease is due to the dynamics of the reduction in the amount of premiums collected, which will exceed the reduction in compensation paid as some companies waive their 
membership of the fund (the membership fee being too expensive in relation to the individual riskiness of the farms in question) and those remaining in the fund will be characterized only by those subject to higher risk. The assets will continue to decrease with increases in the premium to reach a zero level at levels of membership fee that are prohibitive even for farms characterized by the highest value of willingness to pay.

The operation of a national mutual fund will be sustainable to the extent to which there are levels of membership fee for which, on the one hand, there are companies willing to adhere to the fund and, secondly, there is a dynamic sustainability (over time) of the fund (net of subsidies for the recapitalization of the fund's losses).

The Farm Accountancy Data Network (FADN) years 2007-2012 provided data used for the simulation. The number of farm jointly recognized in each year of the reference period is 5.921 and excluding those with negative average income references-unable to afford the required membership fee for the mutual fund-the total number of farms involved is 5.711.

\section{Estimating the Potential Demand and Costs for IST in Italy}

To conduct simulations closing to the reality, it has been decided to operate by defining the composition of the portfolio of the potential participants. It is assumed as the relationship between participants with different levels of risk. Therefore the level of costs (both private and public) will highly depend on how much it is decided to sway the portfolio of members towards opposite levels of risk (It is implicit that the fund will need to have a system for the identification of risk of each farm in order to differentiate the individual contribution of investment in the fund).

Results show that for an individual membership fee request equal to $10 \%$ of the add value generated by the farm, demand involves about $75 \%$ of the total for the selected sample.

If the threshold of the minimum price of adhesion is raised, for example to $15 \%$ of added value, the percentages of participation are reduced to $50 \%$ about.

In order to estimate the cost of the measure we start from the gross salable (agricultural) production GSP insured today in Italy, approximately $20 \%$ of the national total and the required premium (net of the public contribution) to the underwriters of the policies (ranging from $3-4 \%$ of the GSP up to higher rates because of the type of production insured, single or multi-risk and geographical location of the company), we estimated the possible cost to the public for the IST.

The idea was to look for a tool capable of capturing a demand slightly less than that insured today. A realistically ambitious goal, especially when one considers that this level of participation is not considered a substitute for the current demand for insurance, but alternative and/or complementary to it.

Thus the reference value was set between 15 and $20 \%$ of national GSP. At this point, two simulations were conducted, using different assumptions, but both based on the estimation of the WTP with the aim of verifying the robustness of the results obtained.

For the first simulation we chose to operate "realistically" on the sub-sample of farms that in the reference period recorded a Value Added average $\geq$ 20,000 euros (3.602 business units) (The possibility of operating on the sample of farms already insured was discarded in order to have a sample as representative as possible of all the production systems and the entire national territory. The major distortions derive from the fact that farms that have signed insurance policies are almost exclusively located in the centre and north of the country, large in economic terms and suited to the production of fruit and vegetables and wine), extrapolated to the entire target group. For these farms a membership mechanism was proposed that foresaw a minimum payment of $10 \%$ of the average VA of the three years preceding accession, plus $75 \%$ of the difference over and above this minimum and its WTP.

The results of the simulation indicate that if the premium asked of the companies is in relation to the risk they exhibited, under the assumption of contributions set out above, the estimated cost of any public intervention would oscillate between 220 and 260 million euros for 2008, dropping to 202-220 million euros for 2009 and would cover about a quarter of the national added value (for between 85,000 and 100,000 farms).

As mentioned above, in order to evaluate the "robustness" of the results obtained, a second simulation was carried out that differed from the first in some of its operating assumptions. In particular, while still examining the WTP which, it should be remembered, is taken as a proxy for the riskiness of individual farms, the hypothesis worked under the assumption that, in order to ensure the sustainability of the fund, it is essential that it maintain a reasonable ratio between contributions and pay-outs.

In this regard, reference was made to the profile of the farms that resort to the insurance market for risk coverage. In this market, in the period 2005-2009 the pay-out to premium ratio stands at an average of $68 \%$, with a percentage of the total insured companies compensated approaching 20\%. Knowing, therefore, the "structure" of the insurance portfolio of companies and the WTP of the sample, it was possible to prepare a sub-sample that had characteristics similar to those found for the insurance portfolio. 
In detail, the procedure involved the selection from the reference sample (5,711 firms) of all healthy farms and the random selection (without re-immision) of a number of companies suffering eligible losses such as to have present in the sample, at a constant rate over the years examined (It is plausible to imagine that over the years the fund will maintain a portfolio structure that can remain viable (by assumption constant) regardless of the variation in the number of participating companies. In particular, the simulation was conducted considering, for the year 2009, the same sample of farms as those taking part in 2008 plus a number of companies so as to provide the percentage of farms in default on the total to $20 \%$ ), an incidence ratio for these farms within the total of $20 \%$. Furthermore, a level of private contributions was determined able to cover the estimated losses prior to public refinancing and to ensure-net of this refinancing-a ratio of pay-outs to premiums close to the mean found in the insurance sample, at least for the first reporting year (2008) (One should bear in mind that in the insurance market, the differential between the premiums and payouts is kept by the insurance company whereas in the case of a mutual fund these resources remain available to the members for the period following, bringing about a probable variation of relationship between the money entering the fund and the sums being paid out as compensation). In this regard, assuming a minimum private contribution of at least $5 \%$ of the average reference earnings, which resulted in the exclusion of firms with less willingness to pay less than the contribution requested (WTP $<0.05$ ), while for the others the participatory contribution was determined in relation to their perceived risk:

From (2) if $W_{T P}(\Psi) \geq \pi_{i} \mathrm{WTP}_{\mathrm{i}}(\Psi) \geq \pi_{\mathrm{i}}$ then: with $0.05<W T P_{i}<0.10$ it follows that $\pi_{\mathrm{i}}=\mathrm{h}_{\mathrm{i}} * 0.05$ with $0.10 \leq W T P_{i}<0.30$ it follows that $\pi_{\mathrm{i}}=\mathrm{h}_{\mathrm{i}} *\{0.05+$ $\left.\left[\left(\mathrm{WTP}_{\mathrm{i}}-0.05\right) * 0.25\right]\right\}$

with $W T P_{i} \geq 0.30$ it follows that $\pi_{\mathrm{i}}=\mathrm{h}_{\mathrm{i}} *\{0.05+$ $\left.\left[\left(\mathrm{WTP}_{\mathrm{i}} 0.05\right) * 0.75\right]\right\}$

In this way it was possible to create a sub-sample consistent with the portfolio hypothesis set out above. Obviously, it is easy to observe that the identification of a single sub-sample could distort the results of the calculations due to the income characteristics of the companies included/excluded from the portfolio. To overcome this problem, it was decided to extract-randomly and with re-immision-a large number of sub-samples (The extraction, for the operating limits of the adopted version of the statistical programme (STATA 9.2) was repeated 800 times. However, the number of repetitions is sufficient to allow the estimated data to converge to the actual value (simulation test conducted on the total sample of 5,711 firms) in order to make the estimated figure converge (the average loss of income to be compensated) with the real value.
The estimated average loss to be compensated for the year 2008 (4,042 companies), considering a confidence interval set equal to twice the standard deviation is between 4,516.67 and 5,365.56 euros per farm, while for the year 2009 (4,494 companies), these values decrease, respectively, to 4,035.56 and 4,711.11 euros per farm. Similarly, on the basis of the pricing scheme above, the private costs of participation per company were estimated. In this case, ranging from a contribution of between 5,259.34 and 5,611.51 euros per company for the year 2008 to only slightly lower contributions in the year 2009 (between 5,147.52 and 5,394.19 euros per company).

With this data it is possible to simulate the operation of the mutual fund for the biennium 2008-2009, assuming a public intervention of an ex-post type and $65 \%$ compensation paid by the fund for farmers, in line with the provisions of the current proposal for Rural Development Regulation.

The results, under the hypothesis that the fund involves 90,000 farms (The hypothesis of accession to the fund for 90,000 farms was made in view of the degree of participation of enterprises in the agricultural insurance market. In this way, albeit with the inevitable inaccuracies due to the nature of the sample used, it is possible to estimate the results from the fund for the protection of approximately $20 \%$ of the gross national saleable product) and to account for the entire estimated loss $(70 \%$ of the allowable loss according to the IST measure), are shown in Table 2 and 3.

As can be seen from the data reported in Table 2, the private contribution and the public topping up enable the Fund to always achieve a positive balance. In particular, from Table 3, we can see that the estimated costs for the public operator are quite consistent with those inferred from the first simulation (Table 1), although it tends to prove rather larger. These results therefore suggest a condition that is slightly more pessimistic, but still useful to define a range of variation of public expenditure under different operating assumptions.

As can be seen from the data reported in Table 2, the private contribution and the public topping up enable the Fund to always achieve a positive balance. In particular, from Table 3, we can see that the estimated costs for the public operator are quite consistent with those inferred from the first simulation (Table 1), although it tends to prove rather larger.

These results therefore suggest a condition that is slightly more pessimistic, but still useful to define a range of variation of public expenditure under different operating assumptions.

Table 1. Hypothesis 1, Estimated public cost, two year period 2008-2009, values in thousands of Euros

\begin{tabular}{lll}
\hline Year & Min & Max \\
\hline 2008 & $€ 220.120,00$ & $€ 260.400,00$ \\
2009 & $€ 202.250,50$ & $€ 220.400,00$ \\
\hline
\end{tabular}


Table 2. Hypothesis 2, Simulation of a mutual fund covering 90,000 farms, values in thousands of euros

\begin{tabular}{lllll}
\hline 20082009 & MINMAX & MIN & MAX & \\
\hline A)Private contribution & $€ 473.340,60$ & $€ 505.035 .90$ & $€ 463.276,80$ & $€ 485.477,80$ \\
B)Fund capital & $€-$ & $€-$ & $€ 331.065,60$ & $€ 336.020,90$ \\
C)Losses to reimburse & $€ 406.500,00$ & $€ 482.900,00$ & $€ 363.200,00$ & $€ 424.000,00$ \\
A+B-C (se $<0$ : loan or reinsured) & $€ 66.840,60$ & $€ 22.135,90$ & $€ 431.142,40$ & $€ 397.498,70$ \\
Public refinancing & $€ 264.225,00$ & $€ 313.855,00$ & $€ 236.080,00$ & $€ 275.600,00$ \\
BALANCE & $€ 331.065,60$ & $€ 336.020,90$ & $€ 667.222,40$ & $€ 673.098,70$ \\
\hline
\end{tabular}

Table 3. Hypothesis 2, Estimated public cost for 90,000 farms, values in thousands of euros

\begin{tabular}{lll}
\hline Year & Min & Max \\
\hline 2008 & $€ 264,225.00$ & $€ 313,855.00$ \\
2009 & $€ 236,080.00$ & $€ 275,600.00$ \\
\hline
\end{tabular}

\section{Conclusion}

The Income Stabilization Tool (IST) is one of the major novelties of the proposed Regulation for Rural Development 2014-2020 and entails a quantum leap compared to the risk management measures currently available under the CAP. The IST aims to protect farmers from the risk of excessive reduction in annual income, providing comprehensive coverage, not limited to traditional production risks, but extending to any event which may have a negative impact on farm income.

Given the innovative scope of the measure and the benefits that it can bring to an agricultural sector increasingly exposed to fluctuations in international markets, it seemed appropriate to verify its applicability and sustainability within Italy in the medium and long term.

This check came from an analysis of the proposal from the Commission, within which certain critical elements were identified, some general, others more specific and linked to the hypothesis for the implementation of the instrument in the Italian context. These critical issues were raised by Italy as part of negotiations on the proposed EU regulation, accompanied by requests for amendment.

In general, the measure would be better placed in the first pillar, given the voluntary nature of operations and the variable financial capacities of the different Member States. Its location in the second pillar could lead to its uneven implementation, resulting in unequal treatment for the farms.

The operation of the measure also appears poorly compatible with the management rules applying to rural development programmes, based on the principle of automatic disengagement. Great uncertainty surrounds the IST with regard to the estimates of expenditure for two reasons:

- As a new measure it is difficult to make accurate predictions about the number of farms taking part

- The diverse nature and often systemic aspects of the risks covered make it difficult to estimate the annual value of any losses incurred
Under such conditions of uncertainty, it becomes risky to programme the measure, particularly in Regions with large budgets and little aptitude for risk management by farms, as is the case for various Italian Regions.

Making management of the measures easier could be guaranteed by a change in its operation, which would foresee the provision of public contributions, not to cover the part of the compensation paid-out to the fund members (as proposed), but directly towards the annual payments the members make (according to the procedures followed for insurance policies). Such a model would, in addition, provide more incentives for companies and encourage greater participation.

Finally, with specific reference to the Italian situation, the current draft regulations require the implementation of measures of risk management on a Regional basis, because no National measures or programmes alongside the PSR are foreseen. The establishment of Regional funds, however, would not allow for the necessary diversification of any risk portfolio in terms of area and sector and would make the implementation of the measure difficult in Regions where there is less propensity towards risk management.

Regardless of the resolution of doubts at the EU level and the critical issues raised, in order to evaluate the implementation of the IST in Italy it is necessary to estimate the cost of the instrument and verify its sustainability over time.

Making use of the only data source currently available, the FADN sample of farms for the period 2005-2009, an estimate of potential demand that exists for the instrument has been produced together with the annual cost in terms of public spending.

The estimate was carried out assuming the achievement of a target of about 85,000 to 100,000 farms, representing $15-20 \%$ of the national Gross Saleable Product, established on the basis of the current distribution of insurance policies. It is important to note that the estimate is not based on an assumption of a replacement of these policies with IST adherence, but 
the idea that this tool could go to meet a potential demand for protection against fluctuations in income that is not met by the current insurance on offer, which as we know, is unable to adequately cover certain sectors and geographical areas.

The annual cost, estimated at between 200 and 260 million euros, is in line with the public cost associated with the insurance instrument for a similar number of farms covered. The amount also seems compatible, except, of course, for the strategic choice that lies with the chief administrators of such programmes, with an overall budget for rural development, which would still be more than 2 billion euros per year.

The cost estimates cited above, come from a simulation of the fund, according to which the annual membership payments for each member is linked to his or her income risk. In this sense, to obtain a complete project for the implementation of the measure, it is necessary to deepen the analysis towards a model of risk assessment for each participant based on their earnings history and, if possible, on the farm's location and sector.

Within the same analysis the operation of the fund was simulated to ensure its economic and financial sustainability over time. The tool proved sustainable although the limited time series available for income data does not allow a solid assessment with reference to the long term.

Finally, even considering the as yet provisional nature of EU rules and analysis efforts still required to arrive at a complete plan for implementing the measure, it would be appropriate to immediately initiate a national administrative 'itinerary' that would make it possible to fully grasp the opportunities offered by this new planning tool without delay.

In this sense, it would seem necessary to identify a common strategy at the national level in the field of risk management, on the basis of which to proceed to the establishment of the necessary framework. A single strategic approach will be necessary, regardless of the results of negotiations on the new EU regulation, as well as that for the possible establishment of the IST, including the implementation of the system of incentives for insurance policies, which surely cannot be abandoned under the terms of new programme and the management of which is unlikely to be completely transferred to the Regional level, for several reasons related to the effectiveness and efficiency of any intervention.

The operation of IST also requires an underlying national legislation, whose implementation must be started quickly, to avoid delays in the implementation of new programmes.

\section{Acknowledgement}

Authors thanks anonymous referee for helpful contribution to increase the value of the paper; however, authors are responsible for the comments and analysis carried out throughout the text.

\section{Funding Information}

The research project which led the analysis has been funded by National Rural Network, Italian Agriculture Ministry.

\section{Author's Contributions}

Capitanio Fabian: Designed the research plan, organi zed the study and contributed to the writing of the manuscript.

Felice Adinolfi and Jorgelina Di Pasquale: Participated in all experiments and contributed to the writing of the manuscript.

\section{Ethics}

The work carried out in this paper has not been published before on other Journals.

\section{References}

Anton, J., S. Kimura and R. Martini, 2011. Risk management in agriculture in Canada. OECD Food, Agriculture and Fisheries Working Papers.

Cafiero, C., F. Capitanio, A. Cioffi and A. Coppola, 2007. Risk and crisis management in the reformed european agricultural policy. Canadian J. Agric. Econo., 55: 419-441. DOI: $10.1111 / \mathrm{j} .1744-7976.2007 .00100 . \mathrm{x}$

Capitanio, F., M.D.C. Bielza, C. Cafiero and F. Adinolfi, 2011. Does market competitiveness significantly affect public intervention in agricultural insurance: The case in Italy. Applied Econom., 43: 4149-4159. DOI: $10.1080 / 00036846.2010 .487823$

De Castro, P., F. Adinolfi, F. Capitanio and J. Di Pasquale, 2012. The future of European agricultural policy. Some reflections in the light of the proposals put forward by the EU Commission. New Medit J., 11: 4-11.

De Castro, P., F. Adinolfi, F. Capitanio and S. Di Falco, 2011. Building a new framework for the common agricultural policy: A responsibility towards the overall community. Eurochoices, 10: 32-36.

DOI: 10.1111/j.1746-692X.2010.00171.x

EC, 2013. Regulation (EU) no $1305 / 2013$ of the European parliament and of the council of 17 December 2013 on support for rural development by the European Agricultural Fund for Rural Development (EAFRD) and repealing Council Regulation (EC) No 1698/2005 
Enjolras, G., F. Capitanio and F. Adinolfi, 2012. The demand for crop insurance: Combined approaches for France and Italy. Agric. Econom. Rev., 13: 5-22.

Garrido, A. and M. Bielza, 2008. Evaluating EU risk management instruments: Policy lessons and prospects for the future.

Majesky, E., 2008. Sustainable development and sustainable agriculture: Theory and practice of farming.
Meuwissen, M.P.M., M.A.P.M. van Asseldonk, K. Pietola, J.B. Hardaker and R.B.M. Huirne, 2011. Incomeinsuranceas a risk management toolafter 2013 CAP reforms? Proceedings of the International Congress Contributed Paper for the European Association of Agricultural Economists, (AAE' 11).

Pigeon, M., F.B. Henry de and M. Denuit, 2012. Actuarial evaluation of the EU proposed farm income stabilisation tool. 